\title{
Pós-modernidade e ensino de línguas estrangeiras: tendências e desafios
}

\author{
Mariana Rosa Mastrella (MASTRELLA, Mariana. R.) \\ Professora Doutora da Universidade de Brasília - UnB \\ marianamastrella@gmail.com
}

\section{Resumo}

Muito tem sido discutido acerca das mudanças que caracterizam o tempo presente, bem como suas consequências para a forma como o processo de ensino/aprendizagem de línguas deve ser entendido. Parece consenso a necessidade de que ensinar línguas estrangeiras (LEs) se desenvolva hoje sob uma perspectiva crítica, levando em consideração que o tempo pós-moderno, a partir da caracterização de autores como Hall (2003), Giroux (1999) e Bauman (2001), dentre outros, lança questionamentos sobre o que é ciência, quem é o sujeito e também sobre os cânones que tradicionalmente trazem respostas fixas e pré-concebidas acerca do que envolve a vida social. Nesse sentido, este trabalho tem o objetivo de apresentar uma discussão teórica acerca de algumas características que constituem o que se pode chamar de momento pós-moderno, a fim de focalizar desafios que se põem ao ensino/aprendizagem de línguas estrangeiras, mais especificamente em relação a três aspectos: o status das LEs, a questão das identidades e o lugar chamado sala de aula.

Palavras-chave: pós-modernidade, ensino/aprendizagem de línguas estrangeiras, Linguística Aplicada

\begin{abstract}
Much has been discussed about the changes that characterize the present time as well as their consequences to the way the process of teaching/learning languages must be understood. It seems to be a consensus that the teaching of foreign languages (FLs) must be developed under a critical perspective, considering that the postmodern times (according to the view of authors such as Hall, 2003; Giroux, 1999; Bauman, 2001, among others) question what science is, who the subjects are, and also the canons that traditionally bring fixed and pre-conceived answers about our social life. In this perspective, this article aims to present a theoretical discussion on some characteristics of the so-called postmodernity in order to focus on challenges confronting the process of teaching/learning foreign languages, especially concerning three aspects: the status FLs may acquire, identity matters and the place we call language classroom.
\end{abstract}

Keywords: postmodernity, foreign language teaching/learning, Applied Linguistics 


\section{Introdução}

Muito tem sido discutido a respeito do paradigma da pós-modernidade para se entender o tempo presente: as mudanças ocorridas com a entrada no novo milênio; as dificuldades éticas, sociais, econômicas, culturais, ambientais; o desespero pela sobrevivência que caracteriza as comunidades espalhadas pelo globo; as oportunidades e possibilidades de mudança a partir do que pode ser feito; enfim, são muitos os aspectos que caracterizam esse novo paradigma. São tantos que não há um consenso a respeito do que realmente vem a ser esse tempo que tem sido chamado de pós-moderno. Santos (1999) diz que vivemos numa fase de transição paradigmática entre a modernidade e um novo paradigma, o qual para ele ainda está sem nome, mas que tem sido chamado de pós-modernidade. Mesmo em face da dificuldade de definir o que vem a ser esse momento, o que parece ser consenso é que tem havido mudanças substanciais na vida social no mundo - mudanças que parecem dar sinais tanto de dificuldades críticas, trágicas, que nos levam ao desânimo e até mesmo à sensação de um certo niilismo, quanto de possibilidades e aberturas interessantes para ações especialmente em níveis locais.

Não é interesse deste trabalho abordar o paradigma da pós-modernidade em todos os seus aspectos com profundidade, mas sim apresentar uma visão geral do que o caracteriza de forma que seja possível pensar em alguns dos desafios que ele traz à área de ensino de língua estrangeira (LE) e em especial à língua inglesa (que será discutida aqui para fins de exemplificação). Afinal, se vivemos um novo momento global, o qual traz implicações sobre a vida local, é preciso traçar reflexões sobre ele a fim de que nossas práticas e vivências educacionais, de alguma forma, sejam preparadas para a realidade em que nos inserimos. Para tanto, este artigo recorrerá, a seguir, a teorizações filosóficas e sociológicas a respeito da pós-modernidade, a fim de traçar um caminho que lhe permita instigar reflexões sobre seus efeitos para a área de ensino/aprendizagem de línguas estrangeiras, enfocando de que forma as perspectivas globais lançam desafios à prática local. 


\section{Algumas reflexões sobre a modernidade}

Para entender a pós-modernidade, é preciso vê-la em confronto com os pressupostos do que se convencionou chamar de modernidade. O pós-modernismo, em suas vertentes social, política, filosófica, epistemológica, ${ }^{1}$ questiona os princípios e as premissas do pensamento social e político estabelecidos e desenvolvidos a partir do Iluminismo, os quais marcaram a época moderna. Assim, faz-se necessário caracterizar esta última em alguns de seus aspectos, de forma que possamos contrastá-los com pressupostos importantes do que seria o momento pós-moderno e também para entendermos possíveis consequências desse momento para o processo de ensinar/aprender língua estrangeira.

$\mathrm{Na}$ modernidade, o Homem do Iluminismo era o centro representativo da racionalidade, da possibilidade de uma ciência que o libertasse do dogma que até então o mantinha em dependência de Deus e da Igreja. Esse foi um movimento que precedeu e promoveu o pensamento moderno caracterizando-o como uma época de valorização da pessoa humana como racional, uma racionalidade supostamente capaz de responder às necessidades de compreensão dos eventos da vida do universo. Nesse paradigma, o indivíduo era soberano, no sentido de ser o sujeito da razão, do conhecimento e da prática.

Assim como ocorre com a época pós-moderna, a caracterização da modernidade também é aberta a um enorme debate e pouco acordo. Assim, aqui serão enfocados então dois aspectos que são centrais ao novo paradigma, ou seja, a forma de ver a sociedade e a maneira de se compreender o sujeito. Segundo Giroux (1999), a modernidade se caracterizou em termos de uma dimensão social, a qual corresponde à tradição do novo, ao processo de organização econômica e social realizado sob as crescentes relações da produção capitalista. Essa perspectiva se aproxima de uma ideia burguesa, caracterizada pela

doutrina do progresso, a confiança nas possibilidades benéficas da ciência e da tecnologia, a preocupação com o tempo (um tempo mensurável, um tempo que pode ser comprado e vendido e por isso tem, como qualquer outro produto, um equivalente calculável em dinheiro), o culto da razão e o ideal da liberdade, definidos dentro da

\footnotetext{
${ }^{1}$ Em rápidas palavras: epistemo - conhecimento e logia - estudo, logo, estudo do conhecimento seria o significado do termo. Também o mesmo tem sido usado como estudo do conhecimento do ponto de vista crítico, isto é, do seu valor como teoria do conhecimento para crítica da ciência.
} 
estrutura de um humanismo abstrato, mas também a orientação para o pragmatismo e o culto da ação e do sucesso. (GIROUX, 1999, p. 58)

A razão na modernidade possui um status ontológico, ou seja, ela é concebida como sendo natural, comum e inerente à pessoa humana e, mais que isso, ela é "universalizada em termos cognitivos e instrumentais como a base para um modelo de progresso industrial, cultural e social” (GIROUX, 1999, p. 58), o que faz do sujeito humano a fonte (não o efeito) fundamental de significado e ação. A concepção de história nessa perspectiva é linear, ou seja, os "eventos" históricos são compreendidos como inevitáveis, partes de um processo que se desencadeia por sua natureza desenvolvimental baseada numa ideia de busca por progresso. Assim, a noção de territorialidade geográfica e cultural é construída em uma hierarquia de dominação e subordinação "marcada por um centro e por uma margem legitimados através do conhecimento e do poder civilizador de uma cultura eurocêntrica privilegiada" (GIROUX, 1999, p. 58).

A modernidade também possui uma dimensão estética que pode ser caracterizada por sua tradição de resistência e de oposição aos valores burgueses, através de movimentos da arte e da literatura. O desejo era unir a arte à política, denunciando as desigualdades e injustiças sociais, o que deu grande notoriedade a esses movimentos. Entretanto, o que se viu ocorrer, segundo Giroux (1999, p. 59) foi que "sua postura crítica, sua dependência estética da presença de normas burguesas e seu tom apocalíptico tornaram-se cada vez mais reconhecidos como artisticamente elegantes pela própria classe que ele[s] atacava[m]". Nas análises desse mesmo autor, as dimensões social e estética do modernismo serviram para moldar as disciplinas acadêmicas e o discurso da teoria e da prática educacional, com base nos seguintes pressupostos: 1) criação de uma forte noção de superioridade da cultura elevada sobre e contra a cultura popular; 2) afirmação de um sujeito centralizado, se não unificado, em sua fé no poder da mente consciente, extremamente racional; 3) confiança nesse sujeito com uma capacidade inequívoca de moldar o futuro no interesse de uma vida melhor; 4) celebração da cultura ocidental como sinônimo da própria civilização e do progresso. Também outras críticas são apontadas hoje em relação a esses pressupostos sobre os quais as práticas educacionais modernas são construídas, a saber: 1) a arte moderna tem se tornado um mercado comercial para museus e salas de reuniões de grandes corporações e, quando nas universidades, são abordadas por um discurso despolitizado e 
institucionalizado do que seja arte; 2) a razão e a estética têm se unido para construir um modelo de beleza que é branca, masculina e européia, "com um conceito de maestria que legitima as tecnologias industriais modernas e a exploração de grande quantidade de mão-de-obra das 'margens' das economias do Segundo e do Terceiro Mundo" (GIROUX, 1999, p. 60).

A modernidade também possui uma dimensão política, a qual, diferentemente das dimensões social e estética, não se concentra em questões epistemológicas ou culturais, mas desenvolve um projeto de possibilidade a partir dos ideais do Iluminismo. De forma geral, trata-se da crença na capacidade dos indivíduos de se

comoverem com o sofrimento humano, assim como de removerem suas causas, dar significado aos princípios de igualdade, liberdade e justiça; e aumentar essas formas sociais que habilitam os seres humanos a desenvolver aquelas capacidades necessárias para superar as ideologias e as formas materiais que legitimam e estão incorporadas nas relações de dominação. (GIROUX, 1999, p. 61)

Assim são os discursos da modernidade que se baseiam em uma crença na natureza humana, ou seja, uma natureza que, de alguma forma e em algum momento, obriga o sujeito a sempre se voltar contra o que é opressivo e injusto para si e para os outros. Entretanto, a visão dos estudos da pós-modernidade é de que essa natureza, justamente por não ser natural, não pode ser dada como garantia para superação das injustiças e mazelas que assolam a vida no planeta, pois o que se percebe hoje é que os projetos da modernidade - da razão do homem (sic) como fonte de solução para a construção de um mundo melhor - não se cumpriram. Antes, falharam e tornaram o mundo ainda pior (SANTOS, 1999).

De acordo com Santos (1999), o mundo tem seguido o que pode ser chamado fase de transição entre o moderno e o pós-moderno, pois apesar das mudanças no que se refere à relativização das fronteiras territoriais devido aos processos migratórios, às mudanças linguísticas e identitárias e aos avanços tecnológicos que possibilitam o fenômeno da globalização, ainda vivemos sob os resquícios das dimensões social, estética e política da modernidade. O que chamamos de pós-modernidade, para o autor, não é o simples contrário do moderno, pois o momento de transição o caracteriza tanto em termos de ruptura quanto de continuidade: "há algo de moderno na tentativa de fixação da pós-modernidade" (SANTOS, 1999, p. 103). 
É necessário esclarecer que a pós-modernidade não se constitui em um movimento único, uma teoria unificada. Antes, são várias perspectivas em diversos campos políticos, estéticos e epistemológicos. São vários os movimentos que contribuem para a discussão sobre o paradigma da pós-modernidade, como, por exemplo, as teorias feministas, os estudos culturais e o movimento pós-colonialista. De acordo com Silva (2001), a pós-modernidade tem marcos de início em algum ponto da metade do século $\mathrm{XX}$, embora o próprio autor admita dificuldades quanto ao estabelecimento de datas nesse caso. Para melhor compreender os pressupostos da era pós-moderna, podemos tomá-la em relação à sua postura de negação de três aspectos da modernidade: 1) negação da totalidade da razão e do fundacionalismo; 2) negação das culturas de fronteiras; e 3) negação do sujeito humanista (GIROUX, 1999), todos eles com importantes consequências para a pedagogia de ensino de língua estrangeira.

\section{A pós-modernidade como negação da totalidade da razão}

O movimento pós-moderno se levanta contra todas as formas de totalização, herança deixada pelos ideais Iluministas, pois, "na sua ânsia de ordem e controle, a perspectiva social moderna busca elaborar teorias e explicações que sejam as mais abrangentes possíveis, que reúnam num único sistema a compreensão total da estrutura e do funcionamento do universo e do mundo social" (SILVA, 2001, p. 112).

Para a pós-modernidade, as noções de razão e de racionalidade que fundamentam a modernidade não conduzem ao estabelecimento da sociedade perfeita do sonho iluminista, mas

levam ao pesadelo de uma sociedade totalitária e burocraticamente organizada. Na história da Modernidade, em nome da razão e da racionalidade, freqüentemente se instituíram sistemas brutais e cruéis de opressão e exploração. Tanto as estruturas estatais quanto as estruturas organizacionais das empresas capitalistas, supostamente construídas e geridas de acordo com os critérios da razão e da racionalidade, produzem apenas sofrimento e infelicidade. Visto da perspectiva pós-modernista, o passivo da ideia de razão é bem maior do que seu ativo. (SILVA, 2001, p. 112)

Segundo os argumentos pós-modernos, a modernidade se baseia nas "grandes narrativas", que fornecem explicações universais e totalizantes da vida do universo, unificam a história, a emancipação e o conhecimento. A crítica da pós-modernidade a 
isso é devido ao fato de considerar que elas, as metanarrativas, totalizam a experiência histórica, reduzindo sua diversidade a uma lógica unidimensional e abrangente. As metanarrativas, ou grandes narrativas, não problematizam sua própria legitimidade, negando-se enquanto construção histórica e social, mas autorizando-se como verdades únicas, fechando espaço para a diferença, a contingência, a particularidade: "os apelos à razão e ao consenso, quando inseridos dentro de grandes narrativas que unificam a história, a emancipação e o conhecimento, negam suas próprias implicações na produção de conhecimento e poder" (GIROUX, 1999, p. 67).

Filosoficamente, o pensamento moderno depende de princípios fundamentais que, em geral, se baseiam em noções humanistas de que o ser humano tem certas características essenciais sobre as quais a sociedade deve ser construída, o que caracteriza o pensamento moderno como fundacional. Nesse ponto, a crítica pósmodernista segue ferrenha quanto a essa visão fundacionalista da modernidade, valorizando, em contraposição, o que é histórico e contingente. O termo contingente, nesta defesa do pensamento pós-moderno, ganha um espaço amplo e irrestrito, em que os acontecimentos da vida do universo não trazem em si uma razão fixa de sua existência, mas sim a dúvida e a possibilidade de ser ou não. A primazia do histórico e do contingente atua sobre aspectos como a construção da razão, da autoridade, da verdade, da ética, da identidade. Dessa maneira, o pós-modernismo é radicalmente antifundacional, o que significa rejeitar que amplos esquemas interpretativos possam conectar ou representar todas as coisas, uma vez que esse discurso totalizante da modernidade constitui-se num esforço de fazer sucumbir a heterogeneidade, controlando e dominando as diferenças emergidas em contextos localizados e particulares.

\section{A pós-modernidade como uma negação das culturas de fronteiras}

As fronteiras bem demarcadas que definem o que são as nações, que delimitam identidades nacionais fixas sobre as quais somos acostumados a dizer que "todos os habitantes daquele lugar são assim" são fortes estruturas da modernidade que mantêm a cultura dentro de limites rígidos que, muitas vezes, excluem categorias como as de raça, classe, gênero, etnicidade. A cultura, nessa perspectiva de fronteiras bem delimitadas da modernidade, torna-se um princípio organizador para a construção de limites geográficos que produzem e reproduzem relações de dominação, subordinação e 
desigualdade. Em relação a isso, o movimento da "pós-modernidade constitui uma tentativa geral de transgredir os limites ratificados pela modernidade, de proclamar a arbitrariedade de todos os limites e de chamar a atenção para a esfera da cultura como uma construção social e histórica mutável” (GIROUX, 1999, p. 70). O movimento pósmoderno luta contra a prática moderna de relegar as culturas não-ocidentais à periferia da civilização, tratadas como ramos secundários de histórias, culturas e narrativas insignificantes. Dessa forma,

na era pós-moderna, as barreiras que um dia retiveram a diversidade e a diferença, quer nos guetos domésticos ou através das fronteiras nacionais policiadas por funcionários da alfândega, começaram a ser derrubadas. $\mathrm{O}$ eixo eurocêntrico não pode mais absorver ou conter a cultura do Outro como algo que é ameaçador ou perigoso. (...). A cultura do discurso neocolonial torna-se algo que os Outros têm; é a marca da etnicidade e da diferença. (GIROUX, 1999, p. 73)

A não fixação de fronteiras, característica da pós-modernidade, permite, como corolário, que as identidades também sejam movediças, isto é, não fixas a estruturas culturais que antes participavam na definição de um indivíduo. Com a constante locomoção, com fronteiras fluidas, as culturas se misturam, as línguas se misturam, as identidades se misturam sem que seja possível delimitar ou encontrar algum tipo de "pureza" em qualquer uma delas, já que são todas também indissociáveis umas das outras. Isso pode ser positivamente produtivo à medida que quebra com a lógica única de superioridade de uma cultura sobre outra e abre espaço para a manifestação de outras vozes antes emudecidas.

Entretanto, a existência de discursos que reivindicam espaços que não os da marginalização não significa o fim dos processos que, por outro lado, na própria condição pós-moderna, intensificam a tentativa de manutenção das fronteiras que bem delimitam os excluídos. Se as fronteiras geográficas se tornam fluidas, outras são erguidas.

As obras de Bauman $(1998,2001)$ discutem a questão da pós-modernidade como uma condição tanto de conquistas quanto de privações; tanto de possibilidades de resistência como de imposições trágicas de exclusões. Assim, é importante ressaltar que as exclusões, misérias e mazelas da condição pós-moderna discutidas nas obras citadas desse autor sobressaem apesar de toda a liberdade que os novos discursos de rompimento de fronteiras fixas têm trazido. Em $O$ mal-estar da pós-modernidade, 
Bauman (1998) fala de duas figuras que povoam o mundo pós-moderno - os turistas e os vagabundos - frutos de uma sociedade de consumo na qual a velocidade desenfreada move os desejos e a liberdade de escolha é o bem mais precioso. A velocidade é responsável por comportamentos e expectativas, ao contrário da fixidez que caracteriza a modernidade.

Os turistas e os vagabundos são habitantes do contemporâneo que, segundo Bauman (1998, p. 110), retratam os heróis e as vítimas de nosso tempo. Os turistas são os que podem se mover porque assim o desejam; recusam qualquer forma de fixação e movimentam-se, saem e chegam a qualquer tempo e espaço para realizar seus sonhos, suas necessidades de consumo. É assim seu estilo de vida. Os vagabundos também se movem, mas porque se veem obrigados a perambular por ruas anônimas de inúmeras cidades. São empurrados por uma questão de sobrevivência e sofrem as restrições severas nos espaços de suas perambulações. Sustentam-se do sonho de um emprego qualquer, aceitam tarefas consideradas indesejáveis ou indignas pelos turistas, mas que alguém precisa fazer.

De fato, não se pode desconsiderar que, enquanto formação histórica capitalista, o termo pós na condição contemporânea não significa a superação de todas as mazelas da modernidade nem a certeza das promessas não cumpridas por ela. $\mathrm{O}$ que se vê a cada dia é o aumento da exclusão, a proliferação dos vagabundos e a distância entre suas realidades e a dos turistas (BAUMAN, 1998). Como já foi dito, é importante analisar a fluidez das fronteiras do momento pós-moderno, sem, contudo, ignorar outros tipos de fronteiras que são erguidas.

\section{A pós-modernidade como negação do sujeito humanista}

Uma das críticas mais aguçadas da pós-modernidade à era moderna é em relação à sua noção de sujeito. Para a modernidade, o sujeito é o indivíduo soberano, racional, livre, autônomo, centrado, características decorrentes do domínio da razão e da racionalidade do movimento Iluminista. Sobre essas características, Silva (2001) explica que

no quadro epistemológico traçado pelo pensamento moderno, o sujeito está soberanamente no controle de suas ações: ele é um agente livre e autônomo. O sujeito moderno é guiado unicamente por sua razão e por sua racionalidade. O sujeito moderno é fundamentalmente centrado: 
ele está no centro da ação social e sua consciência é o centro de suas próprias ações. O sujeito da Modernidade é unitário: sua consciência não admite divisões ou contradições (...) [e] sua existência coincide com seu pensamento. (SILVA, 2001, p. 113)

Em alguns trabalhos que discutem a pós-modernidade, a noção de sujeito é concebida de forma bastante diferente. Norton (2000), ao tratar do assunto, dá um exemplo, apesar de admitir o risco de uma excessiva simplificação. Para ela, enquanto o sujeito da modernidade (muitas vezes o indivíduo aprendiz/professor que a área de aquisição de segunda língua retrata) se atrairia por um livro intitulado How to Discover Your True Self (Como descobrir seu verdadeiro eu), o sujeito retratado pela pósmodernidade preferiria um livro com o título It's OK to Live with Contradictions (Não há problemas em viver com contradições). Como consequência do descentramento do sujeito, temos que o mesmo encontra-se, então, fragmentado, em oposição ao seu estado primeiro de unificação. Isso possui um alcance significativo para o conceito de identidade na pós-modernidade. De acordo com Hall (2003), o descentramento do sujeito traz, na verdade, uma crise de identidade para o cenário:

o sujeito, previamente vivido como tendo uma identidade unificada e estável, está se tornando fragmentado; composto não de uma única, mas de várias identidades, algumas vezes contraditórias ou nãoresolvidas. Correspondentemente, as identidades, que compunham as paisagens sociais "lá fora" e que asseguravam nossa conformidade subjetiva com as "necessidades" objetivas da cultura, estão entrando em colapso, como resultado de mudanças estruturais e institucionais. O próprio processo de identificação, através do qual nos projetamos em nossas identidades culturais, tornou-se mais provisório, variável e problemático. (HAll, 2003, p. 12)

Com a crise de identidade do sujeito moderno e a partir da nova forma de encarar sua subjetividade, ele não mais possui uma identidade fixa, essencial ou permanente, mas sim o que Hall (1987) chama de uma "celebração móvel”, ou seja, uma identidade formada e transformada continuamente em relação às formas pelas quais somos representados ou interpelados nos sistemas culturais que nos rodeiam. Essa nova forma de encarar a identidade e os processos de identificação do sujeito pósmoderno traz grandes e importantes implicações para a Linguística Aplicada (LA) e a área de ensino/aprendizagem de língua estrangeira, especialmente no que se refere a questões como língua, poder e identidade, já que definir quem ou o que é o sujeito passa, dentre outras coisas, por esses três aspectos. 


\section{Condição pós-moderna - alguns desafios para a pedagogia de ensino de LE}

Diante dessa caracterização da condição pós-moderna feita até aqui, podemos pensar, não sem razão, que muitas são as implicações desse tempo presente para o ensino de uma língua estrangeira. ${ }^{2}$ Implicações que atingem tanto o nível global quanto o local. Assim, como é proposto por este artigo, serão discutidos aqui as tendências e os desafios que o momento chamado pós-modernidade lança para o processo de ensinar e aprender línguas estrangeiras, em especial o inglês (tomado aqui para efeitos de exemplificação), no que diz respeito a três aspectos: o status das línguas estrangeiras, a questão das identidades e o espaço chamado sala de aula. A questão maior que se objetiva discutir aqui diz respeito aos desafios locais que as mudanças globais impõem. Não se pretende apresentar respostas aos questionamentos feitos, mas sim lançar perguntas que expressam e, ao mesmo tempo, indagam e problematizam os desafios que se impõem a professores e aprendizes de LEs.

Um dos desafios em tempos de pós-modernidade diz respeito ao status adquirido pelas línguas estrangeiras no processo de globalização, de constantes migrações e de diluição de fronteiras. No caso do inglês, por exemplo, é crescente a discussão de seu status de língua internacional de uso entre as diversas comunidades no mundo. Nesse mesmo sentido, tem-se também o surgimento dos chamados vários ingleses (Englishes), os quais, segundo Canagarajah (1999), Pennycook (2001), Moita Lopes (2005; 2006), Rajagopalan (2003), Leffa (2006), Kumaravadivelu (2006), dentre outros, são caracterizados como apropriações do inglês por falantes de línguas e culturas diferentes, os quais então usariam a LE para suas próprias necessidades locais. Essa parece ser uma perspectiva que considera as diferenças entre línguas, entre falantes de várias línguas e, assim, relativiza a necessidade da imposição de um padrão único e imutável a todas as comunidades de aprendizes de inglês como LE.

Entretanto, essa perspectiva global de contato entre línguas nem sempre é acolhida no âmbito local no que diz respeito à educação formal, ou seja, o ensino de inglês (ou outras línguas) em contextos de sala de aula. Um dos grandes desafios da

\footnotetext{
${ }^{2}$ As questões levantadas na discussão sobre as consequências da pós-modernidade para a pedagogia de língua estrangeira terão como exemplos alguns aspectos referentes à língua inglesa, embora vários outros relativos a outras LEs também possam ser destacados.
} 
contemporaneidade é que a educação, de forma geral, tem se mostrado incapaz de transpor as fronteiras entre o moderno e o pós-moderno:

\begin{abstract}
quer-nos parecer que estamos todos atravessados pelas mensagens pós-modernas mas, ao mesmo tempo, imobilizados por elas. Diríamos que nos encontramos num estado de perplexidade frente às exigências da pós-modernidade que se "imiscuem" em nossas salas de aula e que ainda não sabemos como enfrentar. A pós-modernidade nos desafia (...) abalando as certezas construídas em nosso percurso educacional. (AMARANTE, 1998, p. 13)
\end{abstract}

Essa perplexidade também se dá nas salas de aula de inglês como língua estrangeira, por exemplo, onde entramos com teorias sobre globalização, sobre a possibilidade do que chamamos de Englishes (a não existência de um inglês padrão único - características de sintonia com o mundo contemporâneo), mas, quando lá já instalados, vemos permanecer em ação as mesmas velhas teorias sobre que inglês eu ensino e que inglês meus alunos devem aprender (americano ou britânico, para citar um exemplo possível e comum). Essa é uma questão que envolve não apenas professores, mas também aprendizes, que em geral igualmente requerem uma determinada variante do inglês, por motivos que vão desde o status de prestígio até a noção de beleza transferida à língua. De fato, os desafios da pós-modernidade para a prática educacional em LE são muitos e as complexidades seguem um modo crescente.

Outro desafio da pós-modernidade que também pode ser apontado em relação a como vivemos a pedagogia de ensino de inglês como língua estrangeira é quanto à maneira como entendemos o sujeito que habita as salas de aula, ou seja, as identidades tanto de alunos quanto de professores. Certamente, ainda é muitas vezes e em muitos aspectos o sujeito racional e autônomo da modernidade, que através do progresso científico alcançará progresso humano. Se o científico é o que o permite alcançar progresso, então privilegiamos um saber autorizado, central, que deve ser passado, transmitido ao que não sabe, o que legitima hierarquias socioculturais através de um processo de relações desiguais de poder - afinal, em que outro lugar, se não nas práticas educacionais (das quais a sala de aula de LE é afiliada), o papel do intelectual (o professor) é tão enfatizado e a mudança (do aluno) é tão buscada?

A concepção das identidades enquanto móveis, plurais e não fixas, conforme já discutido anteriormente, traz então questões importantes para o processo de ensinar e aprender LEs. As identidades não são estáveis porque elas são construídas na 
linguagem, por meio das relações e dos discursos que constituem a vida social nos seus vários espaços (RAJAGOPALAN, 2002) e elas, as identidades, também não são entidades neutras, mas imbricadas constantemente em relações desiguais de poder. Isso implica, por exemplo, no fato de que determinadas identidades possuem maior acesso, maior prestígio, maior aceitação, etc., do que outras. Dessa maneira, o processo de ensino/aprendizagem de LEs é marcado como espaço de produção identitária, ou seja, lugar onde as pessoas são constantemente identificadas (segundo os discursos circulantes que ditam verdades) como bons/maus aprendizes, que possuem ou não uma boa pronúncia, etc., sendo-lhes garantido ou negado acesso a diferentes possibilidades.

Essas identidades, entretanto, aparecem na sala de aula de LEs como naturalizadas, ou seja, como normais, sem que sejam problematizadas. Em geral, o projeto moderno com heranças do Iluminismo vê a linguagem como veículo neutro e transparente e, na sala de aula de LE, ela é muitas vezes tomada como representação de verdades - as "grandes narrativas" dessa área - sem que seja questionado seu caráter de construção. Esse é um desafio que se impõe para problematização sobre o lugar chamado sala de aula. As grandes narrativas são tomadas como científicas, portanto, válidas como verdade para todo e qualquer indivíduo. Assim, fala-se na LE e sobre a LE sem que se suspeite das "verdades" representadas, sem levar em conta que elas só existem devido a anterioridades históricas que as permitem. $\mathrm{E}$ as verdades, apresentadas nas diversas formas das teorias, respondem prontamente a perguntas, por exemplo, do tipo: como se aprende uma LE? Quem pode e quem não pode aprendê-la? Quem pode ensiná-la?, etc., perguntas cujas respostas muitas vezes impõem exclusões, já que

como outros campos sociais, também o da educação é "governado" pelas categorias que nos permitem nomeá-lo. Em geral, tendemos a ver essas categorias e nomes como resultado de um processo racional e lógico de significação da realidade, envolvendo atores também racionais e razoáveis. Tendemos, por outro lado, a esquecer o quanto essas categorias, conceitos, nomes, taxonomias capacitam ou restringem aquilo que podemos pensar, sentir, dizer, fazer. (SILVA, 2002, p. 254)

Como se pôde ver na citação anterior, as palavras de Silva (2002) devem servir como advertência ao nosso olhar sobre as teorias que ditam como se dá o processo de aprender línguas. O que elas dizem sobre os sujeitos que somos, nós professores e aprendizes de línguas estrangeiras? Ao mesmo tempo, o que deixam de dizer? Essas são perguntas que trazem uma consequência importante para o lugar chamado sala de aula, 
o qual então se configura como espaço de construção de identidades, abarcando discursos que ditam como os sujeitos e os processos de ensinar e aprender línguas devem ser. Isso significa dizer que a sala de aula, enquanto lugar habitado por identidades fragmentadas, não é espaço neutro de transação pedagógica, mas lugar de hierarquias definidas. $\mathrm{O}$ desafio então reside em questionar as teorias que normalizam, isto é, de antemão decidem o "normal" na sala de aula. Assim, podemos então questionar de que maneira a sala de aula abriga práticas interacionais que excluem, concedendo direito à voz apenas aos que apresentam determinados requisitos considerados aceitáveis. Cabem, aqui, por exemplo, perguntas do tipo: quem pode falar na sala de aula? Quem pode responder? A quem é dado crédito e valor? De que maneira a sala de aula estrutura as chamadas interações comunicativas, consideradas de grande importância para a aprendizagem? Quem pode delas participar?

Listar os desafios que, diante de uma nova condição contemporânea da vida social, se apresentam diante de nós não é suficiente para possibilitar que eles sejam resolvidos. Entretanto, suas consequências sobre as realidades com as quais convivemos e também sobre nossa própria forma de enxergar tais realidades deveriam, de alguma forma, nos trazer, pelo menos, certos incômodos e nos colocar em posição de questionar o normalizado.

\section{Considerações finais}

A mensagem pós-moderna confronta-nos, educadores, a todo o momento em sala de aula. São muitos os desafios decorrentes: a cientificidade modernista com ênfase na eficácia do método científico e da objetividade e neutralidade do conhecimento é questionada; o conhecimento é entendido como parcial, local e específico, não universal; o discurso do conhecimento, do saber, não é neutro nem verdadeiro, mas é constituído e constitui relações de poder; a crença do inevitável progresso humano por sua natureza é destruída diante do caos das promessas modernas não cumpridas.

Para fins deste artigo, buscou-se discutir questões da época que agora se chama pós-moderna enfocando que elas impõem desafios à área de ensino/aprendizagem de LEs em relação ao próprio status das línguas estrangeiras, à questão das identidades e ao espaço chamado sala de aula. Aparece como questão primordial o caráter de construção que esses três aspectos (as LEs, as identidades e a sala de aula) recebem, o 
que implica em dizer que nem um deles é tomado como natural, como já dado, como parte normal de um processo previsível. Antes, seu caráter de construção permite e obriga a indagação e o questionamento a respeito de seus aspectos mais básicos, considerados muitas vezes intocáveis.

Os desafios que se põem adiante em virtude do momento em que vivemos, conforme este trabalho buscou analisar, são importantes não apenas para a prática imediata da educação em línguas estrangeiras, mas, de igual modo, para a própria área de conhecimento dentro da qual tal prática se insere. Dessa maneira, é preciso repensar até mesmo a Linguística Aplicada e o modo como esta deve se portar em tempos de novos rumos a fim de realmente se fazer diferença na vida social e com o objeto de que tal ciência se ocupa (a linguagem), conforme conclamam Rajagopalan (2003) e Moita Lopes (2006).

Seguindo na perspectiva da reflexão que este artigo buscou traçar, os desafios que temos no processo de ensino/aprendizagem de língua estrangeira exigem de nós, a meu ver, uma Linguística Aplicada implicada. Implicada em proximidade com o que de fato nós, que habitamos o mundo da linguagem, vivemos; implicada em se fazer presente no cotidiano dos que vivenciam as questões por ela abordadas e seus pontos de vista; implicada em rejeitar uma "natureza" inquestionável que mantém a vida social, com suas injustiças e desigualdades, como está. Implicada em promover espaços para que o que se constitui como direito de todos - como o acesso à aprendizagem de línguas estrangeiras (garantido em documentos oficiais nacionais e internacionais) para a efetivação de uma cidadania local e global - não se realize apenas como privilégio de poucos.

\section{Referências}

AMARANTE, Maria F. S. Ideologia neoliberal no discurso da avaliação: a excelência e o avesso da excelência.. Tese (Doutorado em Linguística Aplicada) - Instituto de Estudos da Linguagem, Universidade Estadual de Campinas, Campinas, 1998.

BAUMAN, Zigmund. Modernidade líquida. Rio de Janeiro: Jorge Zahar, 2001.

BAUMAN, Zigmund. O mal-estar da pós-modernidade. Rio de Janeiro: Jorge Zahar, 1998. 
CANAGARAJAH, Athelstan S. Resisting linguistic imperialism in English teaching. Oxford: Oxford University Press, 1999.

GIROUX, Henry. Cruzando as fronteiras do discurso educacional: novas políticas em educação. Porto Alegre: Artes Médicas, 1999.

HALL, Stuart. A identidade cultural na pós-modernidade. Rio de Janeiro: DP\&A, 2003.

HALL, Stuart. Minimal Selves. In: Identity: the real me. ICA Document 6. London: Institute for Contemporary Arts, 1987.

KUMARAVADIVELU, Bala. Linguística Aplicada na era da globalização. In: MOITA LOPES, Luís P. (Org.). Por uma Linguística Aplicada Indisciplinar. São Paulo: Parábola Editorial, 2006.

LEFFA, Vilson. Língua estrangeira hegemônica e solidariedade internacional. In: KARWOSKI, Acir M.; BONI, Valéria F. C. V. (Org.). Tendências contemporâneas no ensino de inglês. União da Vitória, PR: Kaygangue, 2006. p. 10-25.

MOITA LOPES, Luís P. Inglês no mundo contemporâneo: ampliando oportunidades sociais por meio da educação. Apresentação no Simpósio Inglês no Mundo Contemporâneo promovido pela International Research Foundation for English Language Education - TIRF. São Paulo, 2005.

NORTON, B. Identity and language learning: gender, ethnicity and educational change. Harlow, England: Pearson Education, 2000.

PENNYCOOK, Alastair. Critical Applied Linguistics: a critical introduction. Mahwah, NJ: Lawrence Erlbaum Associates, 2001.

RAJAGOPALAN, Kanavillil. O conceito de identidade em Linguistica: é chegada a hora para uma reconsideração radical? In: SIGNORINI, Inês. (Org.). Lingua(gem) $e$ identidade: elementos para uma discussão no campo aplicado. Campinas, SP: Mercado de Letras, 2002, p. 21-46.

RAJAGOPALAN, Kanavillil. Por uma Linguística crítica: linguagem, identidade e a questão ética. São Paulo: Parábola Editorial, 2003.

SANTOS, Boaventura S. Pela mão de Alice: o social e o político na pós-modernidade. 6 ed. São Paulo: Cortez, 1999.

SILVA, Tomás T. Documentos de identidade: uma introdução às teorias do currículo. Belo Horizonte: Autêntica, 2001.

SILVA, Tomás T. O adeus às metanarrativas educacionais. In: $O$ sujeito da Educação: estudos foucaultianos. 5 ed. Petrópolis, RJ: Vozes, 2002. p. 247-258. 